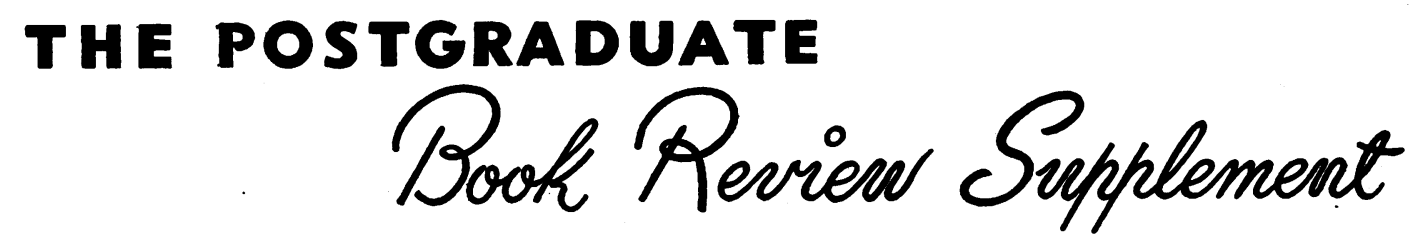

\section{FROM A DOCTOR'S HEART}

By Eugene F. SNyder, M.D. Pp. xvii +25 , illustrated. New York: Philosophical Library. I 95 I. $\$ 3.75$.

This is an account of a physician's illness. It was written by Dr. Snyder whilst convalescing from a myocardial infarction. Besides giving an account of the physical aspects of his condition, he considers the psychosomatic aspects as well. There is a good deal of philosophy to be found in its pages and there is no doubt that this book will find many readers who will both find interest in and take comfort from it. Dr. Snyder has found himself in many difficult situations during his life and he is to be congratulated on writing such a stimulating account of what was his most difficult situation.

L.L.B.

\section{PRINCIPLES AND PRACTICE OF AVIATION MEDICINE}

By H. G. Armstrong, M.D., F.A.C.P. 3rd Edition. Pp. $x+475$, with 95 illustrations. London: Baillière, Tindall \& Cox. 1952. 57s. 6d.

For many years this has been the standard medical textbook, for reference and for study, to practitioners in aviation medicine. The second edition appeared during the war in 1943 and the third edition is therefore long overdue. It is with great pleasure that this third edition is welcomed and due admiration and acknowledgment must be paid to the author, who has succeeded in producing it during his tenure of the post of Surgeon General to the United States Air Force.

The book is intended not only for members of the Armed Services but also for all physicians who may have to render advice to patients wishing to travel by air, or who may have to deal with the removal c casualties by air in connection with civil defence. The author has wisely maintained the general sequence of chapters, and although the index is again somewhat scanty the references, to be found at the end of each chapter, include the best and most informative articles on the great mass of American work which has been carried on $\sin \phi \theta$ and during the war. The general impression 5 gained that the author has been most reluctant to use his official position in the compilation of data and thus the new material introduced to the books can be described as that which has personally irp terested him most and therefore can be safely described as lasting the test of time.

There are, roughly; three parts to the boo: Chapters I to ro deal with the introduction and with methods and problems of selection of flying personnel, including the psychological aspects. Whilst the methods and standards adopted gare those pertaining to the United States Air Force, 4 the general material in this section will be undoubtedly of great value to any practitioner carrying any form of examination on a candidate for flyin duties. The second portion of the book, Chaptens II to $2 \mathrm{I}$, includes most of the material which can be described as fundamental or applied physiolog of flight. It is in this section that the author has shown most restraint in not overloading the tef with irrelevant details of complicated physiologică experimentation. The changes in the material do however, reveal the influence the expansion of knowledge has had upon his treatment of this portion of the subject.

The final chapters on accidents and emotion reactions, air rescue and evacuation, hygiene and sanitation, and protective flying equipment carry general interest to everyone reading the book whether their interest lies in the more administro tive portions of the subjects, or in the practical handling of problems in the field. One has the impression that the author has perhaps had most difficulty with the last chapter in which the material does not always accord with the title. The onfy major omission in this book probably relates to the design of the cockpit and instrumentation of the aircraft in relation to the working environment of the flying personnel. This is somewhat surprising in view of the large amount of published Americen data on this subject.

In general, this textbook can be strongly recommended to all individuals whose interests of livelihood lie in the pursuit of aviation medicine. 